\title{
Study on the virtual reality evolution of modern settlements along Liaohe River
}

\author{
Bo Pan ${ }^{1}$, Dandan $\mathrm{Zhao}^{2}$, Siduo $\mathrm{Liu}^{3}$, Wei Yu \\ ${ }^{1}$ Shenyang Jianzhu University Shenyang, China \\ ${ }^{2}$ Shenyang Jianzhu University Shenyang, China \\ ${ }^{3}$ Shenyang Jianzhu University Shenyang, China \\ ${ }^{4}$ Shenyang University Shenyang, China
}

\begin{abstract}
At the end of Qing Dynasty, with the opening of Yingkou port, the economic exchanges between Northeast China and foreign countries were exported. The transportation of goods was more convenient by water than by land. Liaohe river has become an important road of trade transportation, At the same time, it has also become an important way to culture introduction. Therefore, there are nearly three times more ports along the Liaohe river than before. With each port as the core, gathering the resources of the region becomes the core of transportation. The agglomeration of transportation promotes the emergence of corresponding service facilities and the rapid development of economy.

Among them, Tianzhuangtai, located in the southern edge of Panjin City, bordering Liaohe river in the East and Bohai Sea in the west, is a typical representative of these traditional settlements. It has entered a period of rapid development from a military important town to a trade center since ancient times. The following changes in the settlement space have also shown a trend of development against the tradition, and the evolution of a series of patterns is also the materialization of the special political, economic and cultural influence of the Northeast in modern times.
\end{abstract}

\section{Introduction}

Due to the special climate environment, Northeast China has been the place where minority nationality breed and live since ancient times. The unique regional culture has been brewed out among the White Mountains and black waters. As the "The Land of Dragon Rising " of Manchu in Qing Dynasty This piece of land with Huang Taiji moved the capital to Beijing city and attracted attention. In fact, the construction and development of cities and towns in Northeast China was really realized in modern times, the so-called " go to Manchuria " is defined as the regional boundary of Northeast China. Liaoning, which spans two climatic zones in Northeast China, is developing rapidly under the stimulation of internal and external forces in modern times because of its unique geographical location and climate environment.

\section{The cultural belt moved to the South and Liaohe River bred modern civilization}

In order to protect the land of Dragon Rising, wicker side walls were built twice in Shunzhi and Kangxi periods of
Qing Dynasty. " Outside of the Liutiao sidewall " is designated as Shengjing, while " Inside of the Liutiao sidewall " is Mongolian pastureland, and the other side is forbidden areas such as Royal paddock and pasture, the Liutiao sidewall, from Fengcheng in the South and Xinbin in the northeast to Kaiyuan in the south, Shanhaiguan in the southwest and the Great Wall in the north (need to be checked).This side wall is not only a clear boundary between the Central Plains and politics and economy, but also a dividing line of natural climate, soil characteristics and vegetation in the "North China" and "Northeast China", So far, before modern times, Liaoshen area to the south of Liutiao sidewall was mainly agricultural economy, to the north is the nomadic economy of Mongolia, The economy in the East is mainly agriculture, fishing and hunting, this side wall cuts off the economic and trade exchanges between each other, and people live a self-sufficient life relying on the characteristics and supply of nature in the "delimited" circle.

This change began with the first Opium War in 1840. First, because of the war, the traditional natural economy collapsed rapidly, The land is lost which is farmers depend on, As a result, farmers in Shandong, Hebei, Henan and other places began to " Rush to Northeast" in order to make a living, a lot of refugees poured into northeast, the increase and concentration of floating

\footnotetext{
a15904081234@163.com

b190302262@qq.com

c419041317@.qq.com

d15792683@qq.com
} 
population, promote the development of towns and economic reform.

During the second Opium War in 1858, Niuzhuang was set up as a trading port. While the Northeast foreign trade port was forced to open, Liaohe river, which is connected with Bohai Sea, also opened its short-term and vigorous shipping mission. Driven by the Liaohe river and its tributaries, the economy of the Northeast inland region has also developed rapidly, Along the Liaohe river, according to the needs of shipping, many new towns, large and small, have developed in the form of beads, and each region, with these towns as the center, radiates the regional economic development and promotes the trade and flow of commodities, so far, driven by Liaohe river's shipping, Northeast China has truly become an economic region with internal circulation integration and independent operation, the cultural belt moved to the South and the modern capitalist commodity economy developed rapidly.

\section{A hundred boats competing for the best, rapid growth and development}

Liaohe river is one of the seven major rivers in China and an important navigable river in the south of Northeast China. The rise and fall of Liaohe river shipping is related to the economic development of the whole Liaohe river Basin.

Liaohe river shipping has a long history, as early as the Han Dynasty, there was a saying of rowing, In the Han and Wei dynasties, Liaohe river already had water transportation for military purposes. In the Tang Dynasty, with the development of economy and the progress of navigation technology, the land and water transportation in Liaodong area was more and more developed. In the autumn of 643, Emperor Taizong of Tang Dynasty led 460000 troops to the east of Liaodong, at that time, the grain and grass needed by the army also entered Sancha River from the sea, and then transported to Xiangping via Liaohe river. At that time, the river course was crooked and the transportation distance was long, so it was inconvenient to sail, so Emperor Taizong of the Tang Dynasty ordered people to dig a channel, which is used for boating in summer and ice in winter, it became the main road at that time, It was also the first man-made canal.

Since the Liao, Jin and Yuan Dynasties, the water transportation of Liaohe river was more frequent. In the Jin Dynasty, the government set up a special organization in Kaiyuan to manage the shipping of Liaohe river and Songhua River. During this period, agriculture in the lower reaches of the Liaohe river achieved certain development, with the increase of grain production, the government tried to transport grain from Liaodong area to Shandong, Hebei and other places through Liaohe River shipping and sea transportation, help the victims. In the Yuan Dynasty, Liaohe river was still an important waterway in the south of Northeast China. Large ships often sailed in the lower reaches of Liaohe river or upstream to Liaoyang via Taizi River. In 1267, the Yuan Dynasty established seven water transportation stations in the middle and lower reaches of Liaohe river, and set up water transportation officials in Liaoyang and other places in 1354.

In Ming Dynasty, in order to meet the needs of military transportation, the government extended the route of Liaohe river to Laomi Bay of Kaiyuan, realizing the navigation of the middle and lower reaches of Liaohe river. After the Ming dynasty ruled Liaodong, it sent heavy troops to garrison Liaodong, in order to ensure the supply of grain and copper for officers and soldiers stationed in Liaodong, the imperial court took Dengzhou and Laizhou of Shandong Province as bases for grain and copper support, Before the Ming Dynasty, the Liaohe river Route reached Liaoyang as far as possible. During the 50 years from Hongwu to Yongle, this route never stopped.

At this time, the shipping system of the Ming Dynasty continued to develop on the basis of the Ming Dynasty. Northeast China was the birthplace of the Qing Dynasty, the place where the king was founded by his ancestors, In order to prevent the Manchu from being sinicized and to protect the life of the banner, the Qing Dynasty ruled the northeast region for a long time, ordinary people can't go in and out at will. Therefore, Liaohe river shipping is limited in the middle and lower reaches. Before the middle of Qing Dynasty, Liaohe River shipping mainly served military needs, transporting supplies such as army or grain and grass. During the reign of Emperor Kangxi, in order to expel the Tsarist Russian invaders, the land and water transport between Liaohe river, Yitong River and Songhua River was opened up, which ensured the victory of Yaksa's self-defense counterattack. In addition, in every disaster year, the grain harvest in Northeast China is poor, so it needs to rely on the grain within the pass. The continuous supply of grain is transported to Shenyang, Liaoyang and other places through Liaohe river from Dengzhou and other places in Shandong Province. After the middle of Qing Dynasty, with the relaxation of the policy of banning in Northeast China and the increase of grain production, Liaohe commercial transport gradually increased. In order to meet the needs of such commercial transportation, wharves such as Machang and Laodafang have been built along the Liaohe river, from here, the route of Liaohe river went up $340 \mathrm{Li}$, and further approached the grain producing areas. After the opening of Mapenggou Wharf (Figure 1) in Tieling in 1853 (the third year of Xianfeng), Liaohe shipping has accelerated the pace of development. Before the opening of Yingkou port in 1861, the main stream route of Liaohe River had reached 868 Huali, Tieling and Yingkou is connected to form a line, with more than 70 ports. The number of river channels and navigation conditions are the basis of shipping development. Before the Qing Dynasty, almost all the rivers in the Liaohe plain, except the big and small Ling rivers, belonged to the Liaohe river system. These rivers connected with the main stream of the Liaohe river, forming a huge Liaohe river system. 


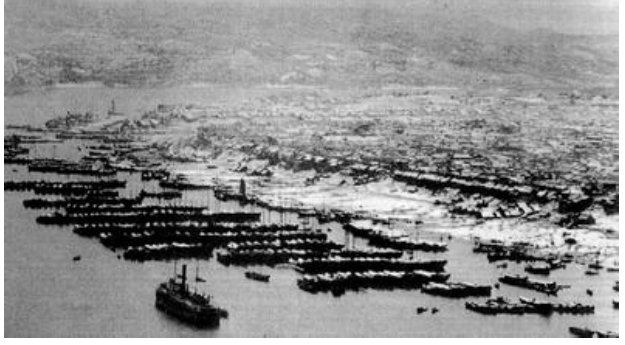

Figure 1 Mapenggou (source: Network)

After 1840, especially after the opening of Yingkou port in 1861, Liaohe shipping entered a period of rapid development. In order to meet the growing demand for shipping, the routes of Liaohe River are constantly expanding, by the end of Qing Dynasty, the main stream of Liaohe River was connected from Yingkou to Zhengjiatun, in addition, the tributaries of Hun River and Taizi River have formed a huge shipping network. In addition, with the prosperity of Liaohe River shipping, the belt shaped urban agglomeration along the Liaohe River gradually formed, which led to the economic development of Northeast China.

\section{A flash in the pan: the survival of the fittest in the old and new modes of transportation}

With the opening of ports, Liaohe shipping is booming rapidly, but this flourishing period did not last long, fter the Middle East Railway was completed and opened to traffic in 1903, the advantages of the railway, such as convenient, fast, super large cargo capacity, relatively low freight, little affected by season, etc., quickly replaced Liaohe shipping and became the main transportation channel. With the development of transportation in Liaohe River, the cities and towns developed in a flash of time are on the decline. The linear urban system along the river and the position of regional agglomeration core are also replaced by the towns where the train stops.

\subsection{The spatial pattern of free growth and street texture}

- Background: economic demand promotes shipping settlement

At the end of the Qing Dynasty, with the opening of Yingkou port, the economic exchanges between Northeast China and foreign countries were exported. The transportation of materials by water was more convenient and faster than by land, therefore, there are three times more ports along the Liaohe river than before, with each port as the core, gathering the resources of the region has become the transportation core. At this time, the traditional settlements along the Liaohe River can be divided into two types according to the different reasons and background, one is the recovery and expansion of the original shipping function. Liaobinta village, subordinate to Gongzhutun Town, northeast of Xinmin City, Shenyang City, Liaoning Province, it can be said that the ancient village of Liaobinta has a history of more than
1000 years. It experienced the glory and decline of Sui, Tang, Liao and Jin Dynasties, it has accumulated rich historical information and carried the changes and development of culture, until the Ming and Qing Dynasties, due to the rise of shipping again, the early Republic of China declined, which has become one of the rare historical and cultural villages in Shenyang. In the early Sui Dynasty, Emperor Yang of Sui Dynasty conquered Koguryo and occupied the city of Liaobin, according to the chronology of historical events in Shenyang, it is recorded that: In 611 ad, Li Jing, Duke of the state of slippery state of Sui, was ordered to March eastward. First attack the garrison cities of Koguryo on the right bank of Liaohe River, such as "wuliluo" (near Liaobin tower and Gongzhutun, Xinmin City, Shenyang), then he forced his way across the Liao River and went deep into the hinterland of Liaodong, it was the beginning of the eastern expedition of the Sui Dynasty, named "Tongding town". The next year, the city was overhauled. After the death of Sui Dynasty, it was occupied by Gaogouli for more than ten years. In 645 AD, Taizong captured Tongding town on behalf of Gaogouli, and renamed it "policheng" as Xiangping Shouzhuo (equivalent to the later Jiedu Shi). In the Liao Dynasty, it was the seat of Liaozhou. At the end of Jin Dynasty, xianwannu, a general of Jin Dynasty, fought a vicious battle with Mongolian strange hero Liuge in order to fight for the Liaohe River Basin, the ancient city of Liaobin was completely destroyed and abandoned in the war, and since then it has declined and no one lives. In Ming Dynasty, Liao Binta was an important place for transporting military supplies. After the Ming Dynasty's military supplies to Liaodong arrived in Liaodong area, some of them landed at Lushun, and some continued to go northward. In the early Qing Dynasty, Nurhachi moved a large number of Jurchen from Changbai Mountain Area of Jilin Province to live in Liaobinta area, It also restored the establishment of Liaobinta village and inherited the function of ferry as one of the towns along the Liaohe River shipping. Liaohe River flows through the village in the south, with a length of $2 \mathrm{~km}$; in the west, Xiushui river flows through it, with a length of about $4 \mathrm{~km}$.

The second is the new towns under the demand of modern Liaohe shipping. The desolate Mapenggou in the west of Tieling City (Fig. 7-3-1), it used to be an important commercial port in the middle reaches of Liaohe River. Mapenggou wharf was officially opened in 1853, and was closed in 1929, After Xianfeng, Tongzhi, Guangxu, Xuantong four dynasties, to the 18th year of the Republic of China, there are 77 years of history. According to the records of the second volume of Tieling county annals. Compiled by Huang Shifang and Chen Deyi in the lead printed edition of the 20th year of the Republic of China, the geographical records of Tieling county are as follows, In the early years of Xianfeng in the Qing Dynasty, the trade in Tieling County gradually flourished. Grain was purchased from the land and collected to the overpass factory in Jinzhou. The roads were blocked and banditry was rampant. Therefore, Kairong, the magistrate of the county, and Lu Ji defense, were invited to open the Mapongou River, which is five miles west of the city, and directly transported by Liaohe 
to Yingkou. Similar records are also found in the traffic records of volume 9 of Tieling county annals. Since the third year of Xianfeng in the Qing Dynasty, the general Fengtian played the right to open the Mapenggou river five miles west of the city. It is worth noting that in 1853 (the third year of Xianfeng), Tieling county magistrate Kairong invited Shengjing general Yixing, and then Shengjing general told the emperor to open Liaohe River inland shipping. Therefore, in the first historical archives of China, there is a record as follows: "on March 29th of the third year of Xianfeng, an imperial edict was given to the emperor on March 29. According to the suggestion of the Ministry of housing, Yixing asked the inland river vessels to be allowed to stay in Tieling. From then on, Mapenggou wharf was officially opened in modern times.

- Break the order, appear the spatial pattern and street texture of random growth according to demand

This kind of traditional settlement may have a deep historical origin, but it is depressed with the limitation of shipping; Or small scale, developed and constructed due to regional advantages, However, regardless of the development background, in the late Qing Dynasty, with the rise of Liaohe shipping, these traditional settlements entered a period of rapid development, the rapid are abnormal development under the stimulation of economic interests. With the change of settlement space, the development tendency of tradition also appeared, the traditional Chinese emphasis on ethics and order has been transformed into a tree shaped spatial pattern and street texture that adapts to the rapid change of demand.

Liaobinta village is located in the southwest of Liaohe River and Xiushui River, with ponds around the southeast side of the village. Farmland surrounds the village and embraces the village, like a bright moon, "two water" pattern is very beautiful, abundant water resources at the same time convenient for production and life. This spatial pattern of conforming to nature, taking advantage of nature and applying artificiality embodies the layout concept of "unity of man and nature". In the early modern times, the structure of Liaobinta village is regular and regular, the streets and roads in the village are formed by the division of courtyards, and the similar courtyards form a more homogeneous layout. The street is the main road in the village. The road scale is about $6-7 \mathrm{~m}$; the lane is the branch road of the village, and the road scale is about 3$5 \mathrm{M}$; The road is an access road with a pavement scale, about 2-3m. he connection modes of primary and secondary roads can be divided into three types: cross intersection, dislocation, Y-shaped and T-shaped, among which cross right angle intersection is the main one.

\subsection{Linear gathering area with wharf and market as economic core}

Because of the river transportation, the quay of the settlement becomes the gathering center, The Liao River in Mapenggou, Tieling, is five to seven feet deep, and can only sail by sailboat. In spring and autumn, there are three or four thousand sailboats moored every day. They come and go like shuttles, and their masts are like woods. Thousands of carts and thousands of horses carry goods to and from Tieling City to Mapenggou. The Liaohe River Wharf, which goes deep into the hinterland of Northeast China, has played a great role in promoting the commercial development of Tieling and even the whole northern Liaoning Province. Especially after Yingkou was opened to the outside world in the late Qing Dynasty, the role of Mapenggou wharf was more prominent, and it was an important transit station for river and land transportation in Northeast China. At that time, some goods from Fuzhou, Ningbo and other places to Yingkou would be shipped to Mapenggou wharf again, and then sold to the northeast hinterland; Soybeans, ginseng and other goods from Northeast China will also be shipped to Yingkou in Mapenggou, and then sold to all parts of the customs. Tieling has a local saying to describe the prosperity of Mapenggou wharf, which is called "water carrying gold and road flowing silver".

Because the shipping trade and transportation place of the settlement is the wharf along the Bank of the river, its commercial center is generally distributed along the Bank of the Liaohe River. According to the historical records of Mapenggou Wharf in Tieling (Fig. 2), the summer shipping season is very busy. Shore shipyards, shipyards, shops, restaurants, one after another.

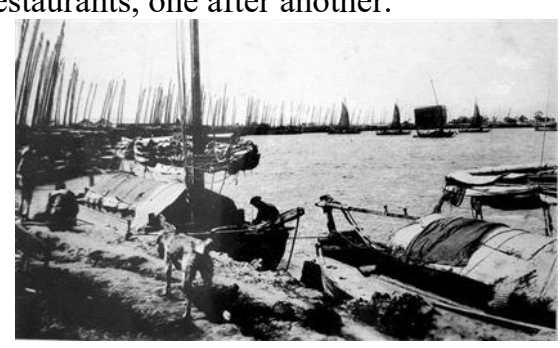

Figure 2 Mapenggou, Tieling (source: Network)

\subsection{Taking religious buildings as spiritual gathering center and settlement commanding point}

The commercial center of the settlement, which was born of Liaohe trade, is wharf and market, while its spiritual gathering center is religious architecture. The distribution and types of religious buildings generally have the following characteristics:

- It is based on the traditional custom of sea and river transportation.

In addition to the Buddhist Liao Bin pagoda, which was built in $1110 \mathrm{ad}$, there are also many temples such as River Temple and Niangniang Temple, which are the traditional gods of Haihe River in China. According to relevant historical records, built in the late Qing Dynasty, the temple worships a goddess of water, which imitates the flood control of Liaohe River and Xiushui river. On the main gate of Niangniang Temple, there are three plaques, namely, It is located in the South courtyard of a folk house in the southeast of the village. It is currently used for planting crops and a broken stone tablet can be found.

- Coexistence of multi religious buildings

The shipping along the Liaohe River not only transported the rich materials of Northeast China, but also 
introduced western religions along the waterway. These new settlements, with economic prosperity, relatively concentrated population, and frequent trade, became the place where missionaries concentrated. In this period, there were Christian churches, Catholic churches and Islamic churches in Tianzhuangtai, which coexisted with the master temple, the empress temple and the medicine king temple.

- Become a cultural center where the settlements gather regularly

Due to the special needs of river transportation, the sacrificial activities are held regularly in the mother temple and the River Temple, while the river movement, as the main support economy of the settlement, has become the spiritual center of the whole settlement. The place space formed for it becomes the centripetal force of settlement.

- The commanding height of settlement space form

In traditional settlements, religious buildings generally become the commanding height of spatial form and become the landmark of entering the settlement. The octagonal 13 storey dense eaves tower of Liaobinta village, which is about $44 \mathrm{~m}$ high, is composed of tower base, tower body, tower eaves and Tasha. The tower base is about $4 \mathrm{~m}$ high, each side is $4.5 \mathrm{~m}$ long and the perimeter is $36 \mathrm{~m}$. The tower body Buddha statue is about 10 meters high, each side has a Buddha niche, carved with sitting Buddha, flanking servant and flying sky. The tower has three palaces - the underground palace, the central palace and the heavenly palace. There are hundreds of copper wind chimes hanging on the cornice, and the ring tone is still clear and crisp.

\subsection{Commercial main street formed by public supporting service facilities}

Because this type of traditional settlement is the economic center of the region, the surrounding villages and towns will gather in the settlement for shipping transactions, However, due to the inconvenience of land transportation in the late Qing Dynasty, the transaction could not be completed in a short time. Therefore, supporting service facilities such as accommodation, catering, leisure, car repair and other activities were provided for merchants, at the same time, as a transportation center, it is also the first access to foreign information, so the influence of western culture is the first to appear in such settlements, There are new types of buildings: banks, hospitals and foreign goods, Through the analysis of the old maps, it is found that in these traditional settlements, public supporting commercial service facilities are mostly linear along the main street. The main street is connected with the river transverse wharf market, and the street scale is wide, At the same time, there are hutongs or sub streets that pass through the main street and are nearly vertical to each other.

\subsection{Multi group group layout of residential buildings with regional characteristics}

The rapid economic development will inevitably lead to the cultural exchange and dissemination, but this passive cultural stimulation is presentational, especially for the traditional settlements with a thousand years of cultural development history, the cultural foundation cannot be shaken in a short time, which is most directly reflected in the residential buildings of traditional settlements.

In the residential buildings of Liaobinta village, courtyard combination is mainly arranged side by side, which is embodied in that the courtyard is vertical to the road, adjacent to the courtyard and arranged along the road direction. Most of the courtyards face south, which is a typical courtyard layout form to strive for sunshine and ventilation conditions. The traditional architecture of Liaobinta village is the continuation of the Qing Dynasty architecture, most of which are residential buildings. Its roof is slightly arched and curved, slightly lower in front and lower in the front and slightly higher in the center, which is called the building of hoarding roof.

There are two factors for the formation of local traditional hoarding buildings. One is the natural environment. There are no hills around Liaobinta village, which is windy and sandy, and cold in winter. The second is the influence of cultural environment. From the Qing Dynasty to the early days of the founding of the people's Republic of China, there were continuous wars in Shenyang, and house design styles could only be inherited through the experience of folk crafts men.

The characteristics of traditional hoarding buildings in different areas are slightly different. The characteristics of the buildings in Liaobinta village are summarized as follows: The main building materials are green brick or red brick body and cement roof; the facade includes two parts: the roof and the body, most of the dwellings in Liaobin tower have no platform foundation; the roof style is mainly hoarding roof; Most of the houses are three or two bays, with a door opening in the middle of the three bays and a door opening in the east of the Double Bay. The chimney can be divided into wall attached type and roof climbing type. The key decoration parts of the building are the dripping tiles of the roof, the lattice of the doors and windows of the house body, the windward stone at the head of the house, and the gable part of the house body.

\subsection{Regional boundary changes from clear to fuzzy and open}

The traditional settlements along the Liaohe River are formed by trade. In the process of historical changes and changes, the boundary of settlements is generally enclosed by Liaohe River and city walls, in the late Qing Dynasty, with the prosperity of Liaohe trade, the wharf became a trade distribution center, where a large number of goods and materials were transferred, Materials from all over the region gather here to board ships, and people regularly come here to buy goods. The substantive boundaries and protection functions of the city walls and gates are gradually weakened, With the widening and 
improvement of the rural road leading to the settlement, it has become an open center for guests from all directions. With the shortage and shortage of land, construction activities have begun outside the city wall, and the regional boundary has changed from clear and clear to fuzzy open.

The ancient city of Liaobin is a square city with rammed earth walls, with a side length of $300 \mathrm{~m}$ and two gates in the north and south. It is the site of the ancient city of liaozhou in the Liao Dynasty. In the Qing Dynasty, the Manchu villagers rebuilt the ancient city wall of Liaobin pagoda and built the city with soil. The city wall was $5 \mathrm{~m}$ wide and could pass.

\section{ACKNOWLEDGEMENT}

Liaoning social science planning fund project 119BKG003

\section{REFERENCES}

1. $\mathrm{Xu}$ Ming; "research on the opening and historical changes of Yingkou port in modern times"; Dalian University of technology; 2008, unpublished

2. Wang Yanyan; "research on the development and utilization of modern northeast water resources"; Jilin University; 2007, unpublished

3. Han Maoli,Liu Xiaoquan, Fang Chen, Zhang Yili Qingmiao, Zhao Yuhui; "The Explanation of the Selection of Settlement and Environment in the Western Liaohe River Valley during the Middle Holocene Epoch"; ACTA GEOGRAPHICA SINICA, 2007, 62(12)

4. Wulan; "Micro analysis of Xiaohexi cultural settlement in Xiliaohe area" Journal of Zhaowuda Mongolian Teachers College 